\title{
A Probabilistic Topic Model on Energy and Transportation Sustainability Perceptions Within Spanish University Students.
}

\author{
J. Rodríguez Pomeda ${ }^{1}$, C.E. Bayas Aldaz ${ }^{1}$, L.A. Sandoval Hamón ${ }^{1}$, F. Sánchez \\ Fernández ${ }^{2} \&$ F. Casani Fernández de Navarrete ${ }^{1}$.
}

\begin{abstract}
Universities gather different social groups with diverse perceptions about sustainability issues. Higher Education institutions are interesting organizations to observe emergent social trends related to environment.

The behavior (inside and outside the university) of those university stakeholders is related to their perceptions about universities' policies and procedures on sustainability.

We focus our research on the students' perceptions on sustainability because of the actual and future role of students within the society.

With 25 interviews (about 55,000 words), we elaborate a probabilistic topic model about the perceptions of a sample of Spanish university students on energy and transportation sustainability referred to their daily activities in the campuses. Students deal with questions about renewable energy, energy efficiency, recycled materials, or bicycle use. The method allows to obtain the main topics underlying the expressed students' perceptions. Corpus' analysis also shows some gaps between students' perceptions and behaviors. Conclusions are relevant not only to know more on students' perceptions about sustainability, but to recommend policies to universities and other organizations.
\end{abstract}

Keywords: Education, Students, Perceptions, Energy sustainability, Transport sustainability, Probabilistic topic models.

\section{Introduction}

The remarkable changes in ecological paradigms at Universities have been to create new balancing between academic, technological and economic growth with environment preservation. Different institutions encourage universities to review their own operations to reflect best sustainable development practices. (UNESCO, 1993)

According to (Foo, 2013) a green campus and sustainable construction connects and organizes every fragmented open spaces or buildings, and facilitates people movement in and around campus under safe and comfortable conditions. Greenery and open spaces are not just amenities, but also an interconnected network of ecological systems that conserve air, water, microclimate, energy resources and enriches human quality of life. Initiatives to commit universities to incorporate management's concept of sustainability in their policies and operations are pervasive.

${ }^{1}$ Department of Business Organization, and Research Institute on Higher Education and Science (INAECU), Universidad Autónoma de Madrid. Spain.

2Department of Social Psychology and Methodology, and Research Institute on Higher Education and Science (INAECU), Universidad Autónoma de Madrid. Spain. 
A Part of this role is to ensure a high quality of life for future generations, and sustainable development is one of the current contexts in which higher education can focus on this mission (Zeegers \& Francis Clark, 2014).

Therefore, this research deals with student's perceptions on sustainability, taking into account students are the biggest part of the university stakeholder's population and also their relevant role in the society. These deep interviews were analyzed using MALLET 2.0.7 (Machine Learning for Language Toolkit) (Andrew Kachites, McCallum, 2002), looking for a probabilistic topic model uses the words of the original texts to discover the themes that run through them, how those themes are connected to each other, and how they change over time (Blei, 2012).

These results would be helpful to define recommendations for green campus initiatives to promote ecological challenges, looking forward to be a sustainable university campus with a healthy campus environment, a prosperous economy through energy and resource conservation, waste reduction and an efficient environmental management, and promotes equity and social justice in their affairs and export these values at community, both at national and at global levels (Alshuwaikhat \& Abubakar, 2008)

\section{Theoretical Background}

According to (Newman, 2006) there is a common understanding in the literature that a sustainable university campus implies a better balance between economic, social and environmental goals in policy formulation as well as a long-term perspective about the consequences of today's campus activities. (del Mar Alonso-Almeida, Marimon, Casani, \& Rodriguez-Pomeda, 2015) Universities play a key role in the development of society, and their involvement in sustainable development will be crucial in changing current practices in society towards sustainable development. Some actions need to be taken to persuade universities to adopt reporting standards and to highlight the benefits and necessity of sustainability reporting.

On the other hand, (Sandoval Hamón, L.A., Bayas Aldaz, C.B., Rodríguez Pomeda, J., Sánchez Fernández, F., \& Casani Fernández de Navarrete, F., 2016) Ecocity and Ecocampus have similar challenges from different scales. In fact, both concepts are interrelated, because both administrations, local and university, should work in coordination to cope with the environmental problems that they have to face. One of the main sustainability challenges faced by today's society and how this vision is applied, under the Ecocampus concept, to the sustainable policies on university campuses. The main initiatives are related with energy and water consumption, transportation and mobility, waste reduction and recycling processes.

Some authors consider that a sustainable university campus should incorporate students' opinions concerning some factors "that contributed to environmental sustainability: green campus operation measures; campus administration, organization, and leadership; teaching, research, and service" (James \& Card, 2012). However, other previous studies have focused on analyze students' environmental awareness based on their daily activities.

Researchers from The Indian Institute of Technology Roorkee studied the perception of the students on the importance of sustainability to the campus. One hundred sixty-five 
students participated in the survey. The survey focuses on four broad categories, environmental, educational, research, and management factors also, the results showed that growing awareness on campus sustainability has resulted into specific practices in energy and transportation. Operational parameters of environmental factors are considered more important compared to the education and management parameters (Bantanur, Mukherjee, \& Shankar, 2015)

Additionally, a questionnaire survey at three Universities of the Comunidad Valenciana, Spain; with a total of 922 students answered the survey. A majority of respondents were not aware of the impact of their daily activities on the environment. $75 \%$ Answered that their daily activity at University does not affect the environment in any way, and only 22.5\% thought it did. (Angeles Ull, Pilar Martinez-Agut, Pinero, \& Aznar-Minguet, 2014) Further, Add to this (de Navarrete, 2015) raises a study of student's perceptions toward Corporate Social Responsibility applying to other Latin American countries, the results showed students' perceptions and attitudes are very positive. However, they consider that sustainability is less important than other more traditional responsibilities of the company. It also shows some differences between countries and women have the more positive attitude towards CSR and sustainability topics.

It is important to point out the role of students' collective behavior considering their environmental impact and their view about universities' sustainability policies and operations.

\subsection{Research question}

Our research question focus on students' opinion as follows:

What are the main topics within students' perceptions about renewable energy, energy efficiency, recycled materials, or bicycle use in their daily activities in the campus?

\section{Methodology}

This study analyzes a social dialogue perspective using a mixed qualitative and quantitative methodology; this is, twenty-five students of ten Spanish Universities were interviewed looking for their views on three principal topics: (1) Level of understanding of sustainability, environment and transport in a general framework. (2) Universities' initiatives and actions about sustainable energy, public transport and mobility. (3) Forward looking approach of Sustainable universities. The set of interviews transcription allows to build a corpus containing about 55,000 words. A probabilistic topic model was obtained on it; the model emerges from "modelling algorithms [that] are a part of machine learning methods for discovering hidden thematic structure in large collections of documents. With a collection of documents as input, a topic model can produce a set of interpretable 'topics' and assess the strengths with which each document exhibits those topics." (DiMaggio, Nag, \& Blei, 2013)

In such a contexts, in the case of (Rodriguez-Pomeda \& Casani, 2016) it research applied topic modeling methodology to the corpus of 100 speeches, with approximately 245,000 words captured, the main ideas and communities behind the prolific production of texts by world-class universities" Presidents, selecting the four main topics allows for the 
simplification of the analysis and the subsequent interpretation of the results.

Based on specific statistical assumptions, a probabilistic topic model called Latent Dirichlet Allocation (LDA) splits the corpus in some "bag of words". LDA (which is the simplest topic model) provides a powerful tool for discovering and exploiting the hidden thematic structure in large archives of text (Blei, 2012). We develop a LDA using MALLET, an open source software that "can help navigate large bodies of information" (Andrew Kachites, McCallum, 2002).

To offer a graphical representation that facilitates the interpretation of the results we used GEPHI "an open source software for graph and network analysis. It uses a 3D render engine to display large networks in real-time and to speed up the exploration" (Bastian, Heymann, Jacomy, \& others, 2009).

We picked up 10 topics to build the LDA model, because the number of topics best suited to the dimension of our corpus, as we explain in the following section.

\section{Analysis of the Results and Discussion}

The following section reports on the analysis of the corpus of the students' interviews, considering the main ideas extracted by MALLET. This open-source software classified the words (see Table 1), and we select ten topics. (Graham, Milligan, \& Weingart, 2016) suggest to choose a small number of topics when the size of the corpus is similar to ours. LDA is an unsupervised method to obtain the topics used to build the texts comprised in the corpus, and also offers the topics' proportion within the corpus.

Thus, to build a graph that facilitates the understanding of the connections between topics and the interviews, we created a bi-modal network visualization (topics and texts, each one of them arise from one student interview transcription), as in Fig. 1. The links between nodes reflects the density of students' interviews in relation to the main topics; therefore "city's future" has a strong connection with interview 1, and less intensive connection with 25, 6 and 17; car-saving and renewable energy are the most used topics and, consequently, connect to most of the interviews. 
Table 1 Keywords of the main topics.

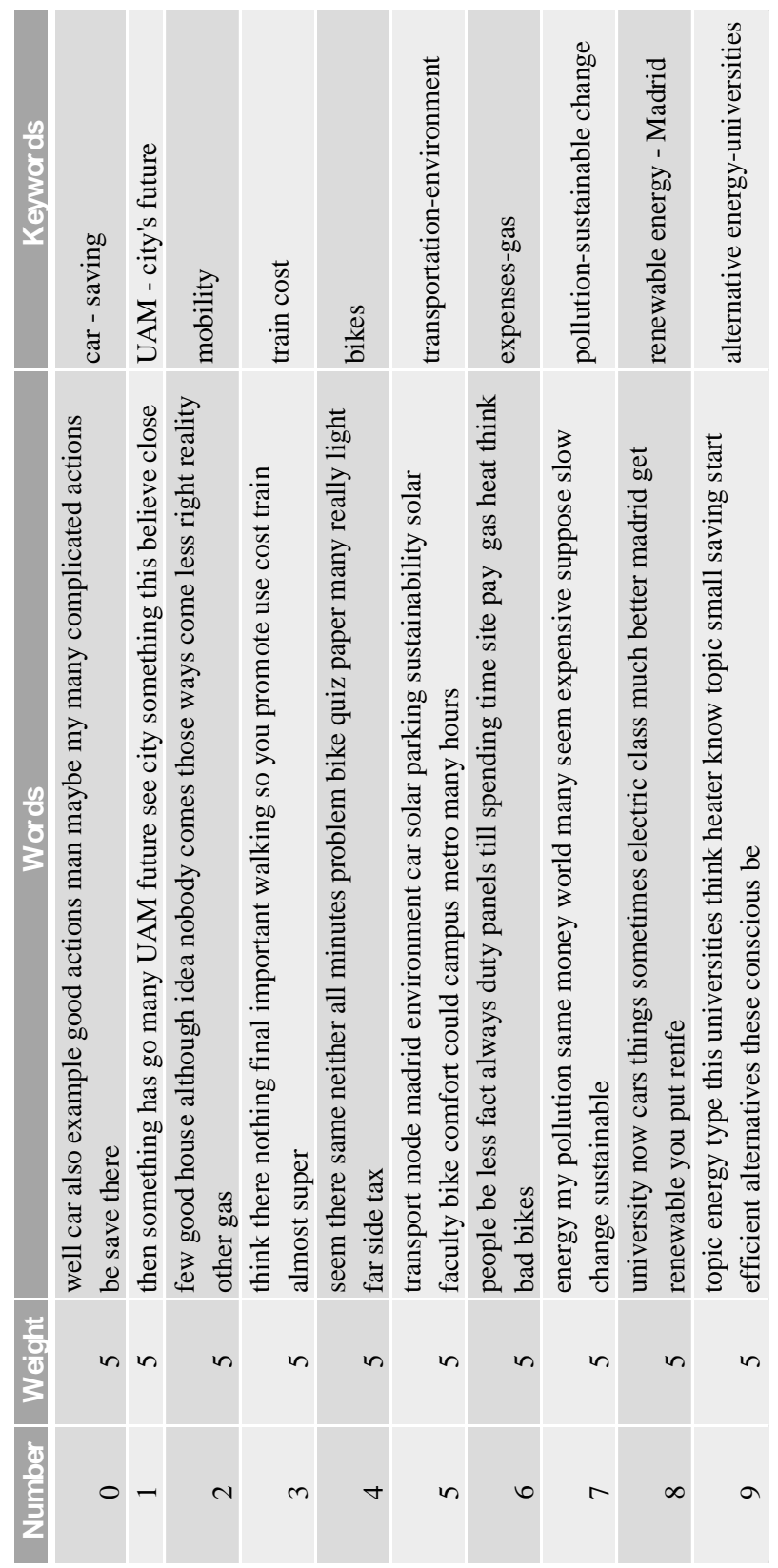




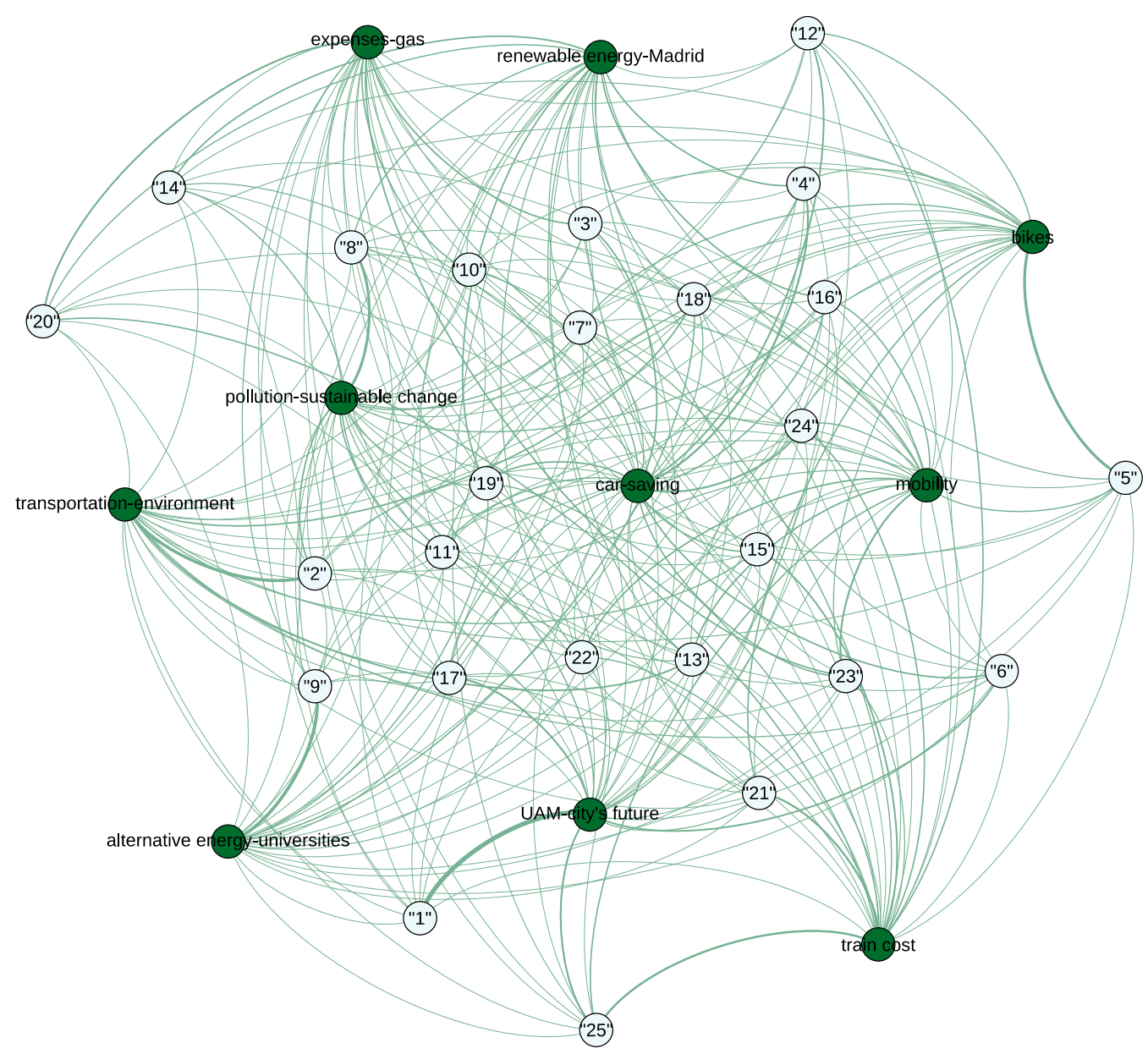

Figure 1 The network of the main topics and students.

The results show that student's perceptions are focused in transport modes to universities; they are also concerned with renewable energy, and mention transportation alternatives like electric cars, and bicycles. On energy efficiency, students advocate improving all the sustainable initiatives implemented by universities, call for a growing environmental awareness, and support a higher consciousness on pollution.

\section{Conclusions}

This paper focuses on Spanish students' perceptions about renewable energy, energy efficiency, recycled materials, or bicycle use in their daily activities in the campus. The method identified 10 main topics related to our research question, which describe firstly the student's concerning of transportations costs, energy use and the inefficient use of our resources.

Additionally, this study show that is necessary to improve a bicycle lane inside and 
outside of universities, to promote the use of bicycles as a mode of transportation. There are also other very important factors related to the mobility topic: comfort, independence, and the time spent with any mode of transportation. Students consider that electric and hybrid vehicles should be a good government's initiatives for transforming transportation in the future.

Finally, in order to become a society more involved in sustainable actions, the majority of the respondents thinks that universities and government have to take effective actions and polices to remove the financial burdens that implies environmental protection today.

\section{Limitations and further research}

We have considered a small sample of student, so it is advisable to develop a larger sample looking for a sound LDA model. Another issue to analyze in the future is the relationship between students' perceptions and behaviors. Both limitations should be considered goals for further research.

\section{Acknowledgements}

This research was supported by the project "Research on energy efficiency and sustainable transport in urban areas: analysis of scientific development and the social perception of the subject from the perspective of metric information studies" (SOENTRAN CSO2014-51916-C2-1-R). Spanish Ministry of Economy and Competitiveness (2015-2018).

\section{References}

Alshuwaikhat, H. M., \& Abubakar, I. (2008). An integrated approach to achieving campus sustainability: assessment of the current campus environmental management practices. Journal of Cleaner Production, 16(16), 1777-1785.

Andrew Kachites, McCallum. (2002). MALLET: A machine learning for language toolkit (Version 2.0.7). UMASS.

Angeles Ull, M., Pilar Martinez-Agut, M., Pinero, A., \& Aznar-Minguet, P. (2014). Perceptions And Attitudes Of Students Of Teacher-Training Towards Environment And Sustainability. In F. Ozdamli (Ed.), 3rd World Conference on Educational Technology Researches 2013, Wcetr 2013 (Vol. 131, pp. 453-457). Amsterdam: Elsevier Science Bv.

Bantanur, S., Mukherjee, M., \& Shankar, R. (2015). Sustainability perceptions in a technological institution of higher education in India. Current Science, 109(12), 2198-2203.

Bastian, M., Heymann, S., Jacomy, M., \& others. (2009). Gephi: an open source software for exploring and manipulating networks. ICWSM, 8, 361-362.

Blei, D. M. (2012). Surveying a suite of algorithms that offer a solution to managing large document archives. Communication of the ACM, 55(4), 77-84.

del Mar Alonso-Almeida, M., Marimon, F., Casani, F., \& Rodriguez-Pomeda, J. (2015). Diffusion of sustainability reporting in universities: Current situation and future perspectives. Journal of Cleaner Production, 106, 144-154.

de Navarrete, F. C. F. (2015). La educación superior como dinamizadora de la responsabilidad social empresarial: un estudio comparado entre los futuros dirigentes empresariales en América Latina. Liber Factory. Retrieved from https://books.google.es/books?hl=es\&lr=\&id=KEAECAAAQBAJ\&oi=fnd\&pg=PA11\&dq=la 
+ educacion + superior + como + dinamizadora + de + la + responsabilidad + social + empresarial\&ots $=\mathrm{S}$ hihW4eFON\&sig=B7IWyUFDBkjHO8JEplccw21GGWc

DiMaggio, P., Nag, M., \& Blei, D. (2013). Exploiting affinities between topic modeling and the sociological perspective on culture: Application to newspaper coverage of US government arts funding. Poetics, 41(6), 570-606.

Foo, K. Y. (2013). A vision on the role of environmental higher education contributing to the sustainable development in Malaysia. Journal of Cleaner Production, 61, 6-12.

Graham, S., Milligan, I., \& Weingart, S. (2016). Exploring big historical data: The historian's macroscope. World Scientific. Retrieved from http://www.history.ac.uk/reviews/printpdf/review/1889

James, M., \& Card, K. (2012). Factors contributing to institutions achieving environmental sustainability. International Journal of Sustainability in Higher Education, 13(2), 166-176. http://doi.org/10.1108/14676371211211845

Newman, L. (2006). Change, uncertainty, and futures of sustainable development., 38(5), 633-7.

Rodriguez-Pomeda, J., \& Casani, F. (2016). Legitimating the world-class university concept through the discourse of elite universities' presidents. Higher Education Research \& Development, 1-15.

Sandoval Hamón, L.A., Bayas Aldaz, C.B., Rodríguez Pomeda, J., Sánchez Fernández, F., \& Casani Fernández de Navarrete, F. (2016). From Ecocity to Ecocampus: Sustainability Policies in University Campuses. International Journal of Sustainable Development and Planning.

UNESCO. (1993). The Swansea Declaration.

Zeegers, Y., \& Francis Clark, I. (2014). Students' perceptions of education for sustainable development. International Journal of Sustainability in Higher Education, 15(2), 242-253. 